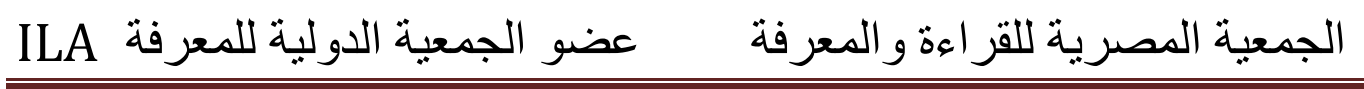

\title{
Using Mimicry Technique to improve Preparatory Stage Students' Pronunciation
}

\author{
By \\ Eman Eldawoody Kholief \\ English Teacher (Damietta University, Egypt)
}

Dr. Adel Abdel Halim Elsheikh

Professor of Curricula

\& Instruction (TEFL)

Mansoura University
Dr.Moataza Muhammad Dadour

Lecturer of Curricula

\& Instruction (TEFL)

Damietta University 


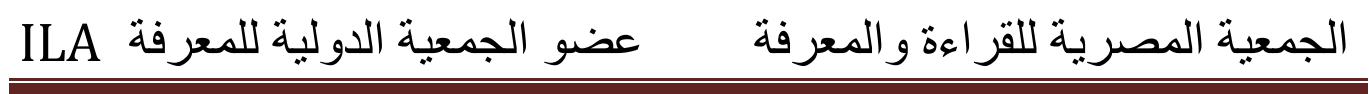




\section{ABSTRACT}

This study aimed at investigating the effectiveness of utilizing the linguistic mimicry technique via Neuron Linguistic Programming to improve preparatory stage students' pronunciation. The researcher adopted Quasi-experimental design. The participants of the study were (60) students enrolled in the first year preparatory stage. They were selected randomly and were classified into two groups: control group and experimental group. Three instruments were designed and applied in this study by the researcher. A questionnaire to determine the most appropriate pronunciation skills for the participants. A prepost pronunciation test to measure the students' pronunciation skills. A rubric was designed to score the students' performance in the pronunciation test. The data were analyzed statistically by using SPSS to measure the difference between the performance of the participants in the pre and post application of the pronunciation test and to measure the differences in their performance in segmental aspects of pronunciation (vowels and consonants) and the suprasegmental aspects of pronunciation (stress and intonation). Results of the study indicated that there were significant differences in participants' performance before and after applying the linguistic mimicry technique via Neuron Linguistic Programming in favor of the post-performance. The study recommended utilizing the linguistic mimicry technique via Neuron Linguistic Programming to develop their students' pronunciation.

Key words: Mimicry, Neuro Linguistic Programming (NLP), and pronunciation. 


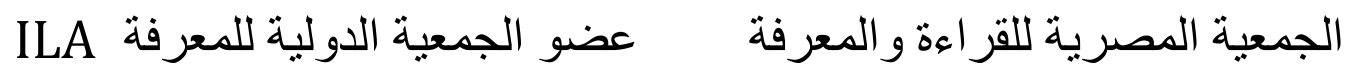

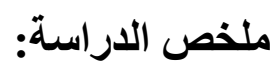

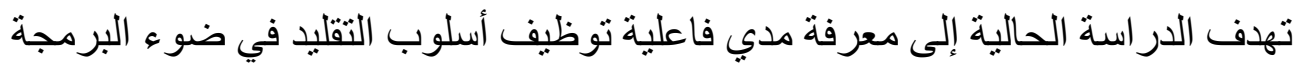

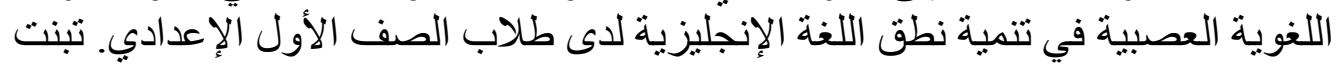

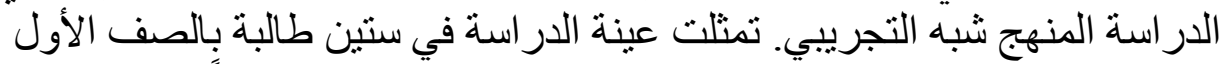

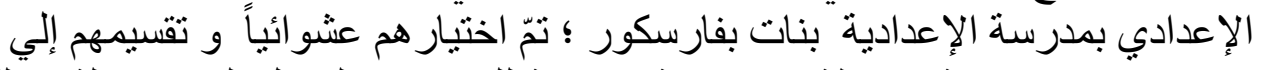

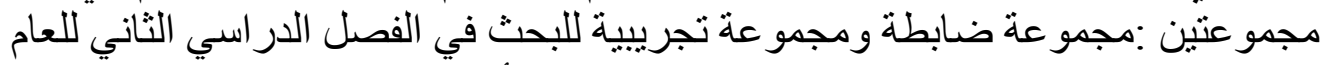

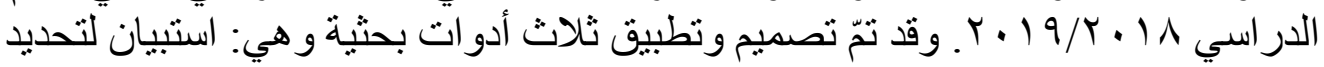

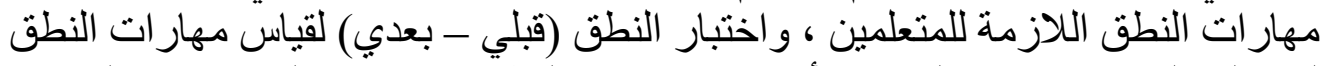

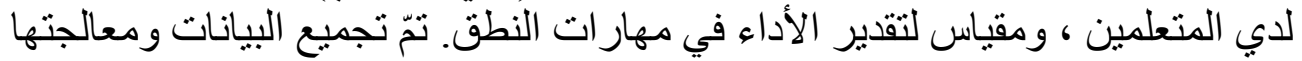

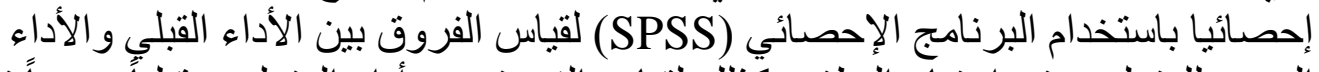

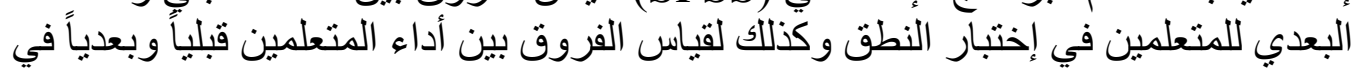

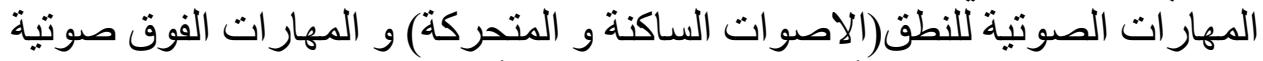

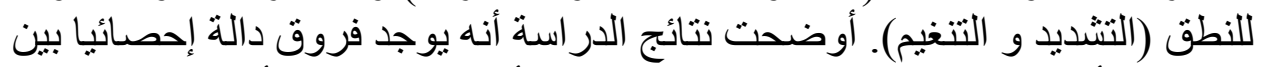

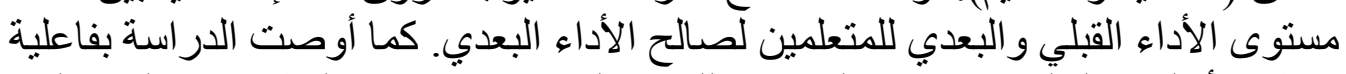
توظيف أسلوب التقليد في ضو والبدي البرمجة اللغوية العصبية في تتمية النطق بالإنجليزية لدى الدى

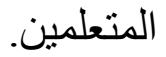


Language is the main means of communication. People use it to achieve various purposes. They use language to express their ideas, feelings and thoughts. In addition people use language to transmit their culture and civilization to others. English is the international language that is used for communication. Therefore, students have to master the main components of the English language in order to be able to communicate successfully with others. These components include phonology, morphology, syntax, semantics, and pragmatics.

Phonology is the study of the sound system of a particular language, and how this system is used to express meaning". Thornbury (2006) Pronunciation is considered one of the most important language components. It has an integral part of foreign language learning because it has a direct effect on both learners' communicative competence and performance (Gilakjani, 2012). Communication is a mutual relation between the speaker and the hearer. This means that one should understand what he hears in the target language and produce the sounds of the language he is attempting to learn. Therefore, learning pronunciation is essential for achieving successful oral communication because pronunciation is a significant element of communicative competence (Hismanoglu, 2006).

People understand learners with good pronunciation even if they make errors in other areas, while those with unintelligible pronunciation will remain unclear, even if they use perfect grammar and extensive vocabulary. (Yates and Zielinski, 2009) Moreover, limited pronunciation skills can reduce learners' self-confidence, negatively affect estimations of a speaker's abilities and restrict social interaction with others (Gilakjani, 2012).

Burns and Claire (2003) believe that learners are no longer required to speak like native speakers but what is significant is that speakers can achieve three basic elements during speaking, namely, intelligibility, comprehensibility and interpretability. Hence, English 
language learners should be able to produce sound patterns that are recognizable as English. They should be able to understand the meaning of what is said and to comprehend the purpose of it. Pronunciation includes features at the segmental (micro) level and the supra-segmental (macro) level. Segmental features have been the main focus for pronunciation teaching. For instance, the teaching of minimal pairs, such as hit/heat, is considered essential in language classes. Recent research has revealed that linking, intonation and stress is significant for effective pronunciation at the suprasegmental level. When teaching concentrates on suprasegmental features, learners' intelligibility is highly developed. As a result, it is necessary to provide language activities at both segmental and suprasegmental levels.

Celce-Murcia, M, Brinton, D.M and Goodwin, J. M (1996) illustrated that traditionally, language teachers have utilized the phonetic alphabet, and activities. They have used detailed description of the articulatory systems, transcription practice, discrimination tasks, production tasks (e.g., minimal pair drills, reading, contextualized sentence practice), games such as Pronunciation Bingo and tongue twisters. Old techniques depended on making students learn sounds and apply them in real speech. Although, some students benefited from these techniques, others faced difficulty to learn pronunciation this way. Teachers should focus on musical aspects of pronunciation more than sounds. They also suggested the use of fluency building activities such as discussion wheel, effective listening exercise, values topics and fluency workshop. They also mentioned that a multisensory mode is considered one of the most effective techniques in developing English pronunciation.

(Hişmanoğlu, 2006) pointed out that recent trends in pronunciation teaching have been affected by several disciplines such as psychology, neuro-linguistics, and sociology and computer 
technology greatly. Currently, the dominant tendency in teaching pronunciation is adopting an interdisciplinary approach which benefits from the results of neurolinguistics. For example, Carballero and Rosado's study (2018) revealed that teachers' use of NLP techniques in their teaching have a positive impact on students' pronunciation. Similarly, Abduloh's study (2018) indicated that modeling NLP technique is effective in developing pronunciation.

This study is meant to contribute to the improvement of learners' poor pronunciation in English through utilizing mimicry technique via Neuro Linguistic Programming. Linguistic mimicry is as an approach which is used to effectively teach suprasegmentals in classrooms. Yates (2003) has found that hrough linguistic mimicry, learners memorize scripts taken from television shows via video and perform simultaneously with the video while linguistically mimicking the actor they are portraying.

Mimicry requires that students imitate every segmental and suprasegmental utterance as well as every physical gesture and facial movement as exactly as possible. Moreover, through dramatic techniques, Linguistic Mimicry provides a non-threatening environment that reduces anxiety and creates a safe environment to integrate the pronunciation of the L2 into the student's personality.

Yates (2003) pointed out that linguistic mimicry considers the three learning styles: visual, auditory and kinesthetic. Students learn visually and auditorily by watching and listening to video clips, with help from the instructor, to identify what forms the English suprasegmentals. By learning to mimic the actions and gestures of speakers, learners can internalize, or feel English pronunciation.

Most people naturally tend to use one system more than the other two, or one system before the others, either when noticing things around them, or when learning something new, which is 
called the preferred primary representational system in NLP. (Winch, 2005)

Fleming (2006) proposed a model which was expanded upon earlier NLP models (i.e. VARK model). In this model, students are classified to four different modes which are based on different senses, namely visual, aural, reading, and kinesthetic. Visual learners have a preference for seeing (think in pictures; visual aids such as overhead slides, diagrams, handouts, etc.). Auditory learners learn best through listening (lectures, discussions, tapes, etc.). (Murphy et al. 2004) pointed out that learners with the tendency of reading prefer printed text to gain information. They like lecture notes, textbooks list and glossaries. They also like to paraphrase classroom notes and arrange lecture notes into sketch form. Kinesthetic learners prefer to learn via experience, moving, touching, and doing (active exploration of the world; science projects; experiments, etc.).

Teachers can use this model to prepare classes that take in to account each of these learning styles.

\section{Statement of the Problem}

Gilakjani and Sabouri (2016) showed that pronunciation has a great effect on learners' successful communication but it is still ignored by many teachers who concentrate on teaching lexis and grammar. Dadour's study (1990) revealed that first year preparatory school students had pronunciation problems. Zayed's study (2003) indicated that pronunciation problems are persistent. It showed that second year preparatory pupils have problems in oral expression skills. In addition, Mater's study (2013) has asserted that first year preparatory pupils have speaking skills problems. Also, Kamal ElDin's study (2014) showed that third preparatory pupils have problems in oral performance skills.

The researcher has noticed that many students still mispronounce some sounds and make mistakes during speaking and $\varepsilon$ 个. 
reading, especially in sentence stress and intonation. Therefore, the present researcher conducted a pilot study to identify the students' level in pronunciation. The sample of the study consisted of 75 pupils in the first year of the preparatory school at Faraskur preparatory school. The students were asked to read a conversation to determine their use of segmental and suprsegmental aspects of pronunciation especially intonation and sentence stress. While the students were reading, the researcher was checking by using an observation card for each student.

Table (1) Percentage of using segmental features incorrectly

\begin{tabular}{|l|l|}
\hline Sounds & Percentage of students replacing sounds \\
\hline$/ \mathrm{p} /$ is replaced with /b/ & $98 \%$ \\
\hline$/ \mathrm{e} /$ is replaced with /ð/ & $98 \%$ \\
\hline$/ \mathrm{g} /$ is replaced with $/ \mathrm{J} /$ & $98 \%$ \\
\hline$/ \mathrm{k} /$ is replaced with $/ \mathrm{g} /$ & $53 \%$ \\
\hline$/ \mathrm{i} /$ is replaced with /e / & $100 \%$ \\
\hline /i: / is replaced with /i / & $28 \%$ \\
\hline
\end{tabular}

Results of the pilot study indicated that first preparatory stage students mispronounced some consonants and vowels. For example, they could not differentiate between the voiced sound $/ \mathrm{p} /$ and the voiceless sound $/ \mathrm{b} /$.Only $2 \%$ of the students who pronounced the sound /p/ correctly.

Table (2) Percentage of using suprasegmental features correctly

\begin{tabular}{|l|l|l|l|}
\hline $\begin{array}{l}\text { Suprasegmental } \\
\text { aspects of } \\
\text { pronunciation }\end{array}$ & $\begin{array}{l}\text { Always used } \\
\text { correctly }\end{array}$ & $\begin{array}{l}\text { Sometimes } \\
\text { used correctly }\end{array}$ & $\begin{array}{l}\text { Never used } \\
\text { correctly }\end{array}$ \\
\hline Intonation & $3 \%$ & $44 \%$ & $53 \%$ \\
\hline Sentence stress & $0 \%$ & $1 \%$ & $99 \%$ \\
\hline
\end{tabular}


As for suprasegmental aspects, results revealed that a small number of students used intonation correctly during reading a conversation. Most of the students stressed every word they read, i.e. they stress both content and function words though only content words (nouns, action verbs, adverbs and adjectives) must be stressed. This means that the students have a problem in both segmental and suprasegmental aspects of pronunciation especially intonation and sentence stress. This shows the importance of mastering both aspects of pronunciation in order to speak English well. This requires adopting a new technique for teaching pronunciation.

Based on the review of literature, results of the pilot study and the researcher experience, the problem of the study is reflected in low performance of the first year preparatory stage students' pronunciation. As a result, the present study tries to solve this problem by utilizing mimicry technique via neuro linguistic programming for developing preparatory stage students' English pronunciation.

\section{Questions of the Study:}

The problem of the study was formulated in the following major question:

\section{What is the effectiveness of the mimicry technique via Neuro Linguistic programming on developing preparatory stage students ' pronunciation?}

This main question is divided into the following sub-questions:

1- What are the pronunciation skills required for the first year preparatory school students?

2- To what extent do first year preparatory school students possess these skills?

3- What are the characteristics of mimicry technique via Neuro Linguistic programming? 
4- What is the effectiveness of the linguistic Mimicry Approach on developing the pronunciation of the first year preparatory school students?

\subsection{Purpose of the Study:}

The present study aimed at:

1. Emphasizing the importance of pronunciation (segmental and suprasegemental aspects) in learning English as a foreign language.

2. Identifying the pronunciation skills necessary for the first year preparatory stage EFL students.

3. Investigating the effectiveness of mimicry technique via Neuro Linguistic programming on developing the first year preparatory stage EFL students' pronunciation.

\section{Significance of the Study}

This study may be significant in enriching the field of teaching pronunciation in schools.

\section{As for teachers:}

- It could Provide English language teachers with an approach that may be helpful and effective in teaching pronunciation.

\section{As for pupils:}

- It could contribute to improve EFL first year preparatory stage pronunciation.

\section{As for course designers and curriculum developers:}

- It could help course designers and curriculum developers in planning the teaching of pronunciation in schools, which, in turn, will help the pupils to pronounce English correctly.

- It could draw the attention of the importance of suprasegmental aspects of pronunciation (stress and intonation) in communication so as to concentrate on them during designing curriculum.

$$
\text { ETr }
$$


- It could enlighten the educational process decision makers of the pronunciation level of preparatory school students so that it could be an indicator to judge the current teaching pronunciation methods.

\section{Delimitations of the Study}

The present study was limited to:

1- A sample of thirty EFL first year preparatory stage students at preparatory school for girls at Faraskor, Damietta governorate in the second term of the academic year 2018/

2- Segmental aspects of pronunciation:

- Consonants $/ \mathrm{p} / / / \mathrm{b} /, / \mathrm{d} /, / / \theta / / / \mathrm{J} /, / \mathrm{t} / / / \mathrm{k} /, / \mathrm{g} / / / 3 /$ and $/ \mathrm{d} 3 /$

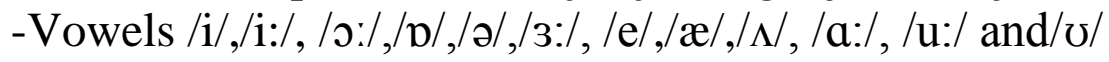

Two suprasegmental aspects of pronunciation ( sentence stress and intonation).

3- "Hello" Text book at preparatory stage one.

\section{Definition of Terms}

\section{Pronunciation}

Burns, \& Claire (2003, p.5) define pronunciation as "referring to the phonology of the language - or the meaningful perception and production of the sounds of that language and how they impact on the listener".

Yates \& Zielinski (2009) defined pronunciation as how the sounds are produced to make meaning during speaking. It includes the particular consonants and vowels of a language (segments), aspects of speech beyond the level of the individual segments, such as stress, timing, rhythm, intonation, phrasing, (suprasegmental aspects), and how the voice is projected (voice quality 
Pronunciation is operationally defined as the ability of first year preparatory school students' to produce different types of sentences with correct phoneme articulation and proper stress and intonation in order to express a number of linguistic functions such as expressing opinions, apologizing, agreeing and disagreeing.

\section{Mimicry}

Yates (2003) defined linguistic mimicry as an approach which is used to effectively teach suprasegmentals in classrooms. Through linguistic mimicry, learners memorize scripts taken from television shows via video and perform simultaneously with the video while linguistically mimicking the actor they are portraying.

Mimicry is operationally defined as the students' ability to imitate a speaker's segmental and suprasegmental aspects of pronunciation to communicate effectively.

\section{Neuro linguistic programming (NLP)}

Revell and Norman (1997) stated that "NLP is a collection of techniques, patterns, and strategies for assisting effective communication, personal growth and change, and learning. It is based on a series of underlying assumptions about how the mind works and how people act and interact" (p. 14).

El-feki (2009) defines Neuro Linguistic Programming as a guide of mind use. He adds that: Programming refers to a group our thoughts, feelings, actions resulting from our habits and experiences that affect our communication with others. Linguistic refers to our ability to use verbal and non-verbal language to detect our thinking styles and beliefs. Neuro refers to our sensory system (five senses) which people see, hear, feel, smell and taste it. 
Bozoğlan (2010) defined NLP as a set of brain-based cognitive techniques to enhance learners' communication strategies and metacognitive perceptions of learning process

NLP is operationally defined as a group of techniques (modeling, anchoring and reframing) based on varied learning styles to improve learners' segmental and suprasegmental aspects of pronunciation. Sample of the Study:

A sample of students from ESL first year preparatory students will be assigned at random into two groups: an experimental group and a control group.

\section{Reasons for selecting the sample of the study:}

1- The pilot study shows that first year preparatory stage EFL students have problems with /in pronunciation.

\section{Instruments of the study:}

The researcher will make prepare the following instruments:

1- Pre-Post pronunciation skills test.

2- A rubric for pronunciation test.

\section{Hypotheses of the study:}

- There is no statistically significant difference $(\alpha \leq 0.05)$ between the mean score of the control and experimental group in the pre-test of pronunciation skills.

- There is statistically significant difference $(\alpha \leq 0.05)$ between the mean score of the control and experimental group in the post-test of pronunciation skills in favor of the experimental group.

- There is statistically significant difference $(\alpha \leq 0.05)$ between pre and post scores of experimental group in the pronunciation skills test in favor of the posttest.

\section{Design of the Study: -}

- The descriptive analytical method to determine and describe the main skills of pronunciation required by the students. 
- The experimental method to test the effectiveness of mimicry technique via Neuro Linguistic programming. The two groups (control and experimental / pre -posttest) design will be employed. The control group will be taught in the traditional way while the experimental one will be exposed to mimicry technique via Neuro Linguistic programming. The effectiveness of mimicry technique via Neuro Linguistic programming will be determined by comparing the mean scores of the two groups.

\section{Results}

In this section, the results of the study are presented in terms of the study hypotheses.

\section{Verifying the first hypothesis}

The first hypothesis stated there is no statistically significant difference $(\alpha \leq 0.05)$ between the mean score of the control group and experimental group in in the pre- application of the pronunciation test. To verify the first hypothesis, the independent samples t-test was used to determine if there was any significant difference between the control and experimental group in in the pretest of pronunciation.

Table (1) Independent samples t-test for the control and experimental group in the application of pre-test of pronunciation

\begin{tabular}{|l|l|l|l|l|l|l|l||}
\hline \multirow{2}{*}{ Test } & Study Group & N & Mean SD & T & DF & $\begin{array}{l}\text { P- } \\
\text { value }\end{array}$ \\
\hline \multirow{2}{*}{$\begin{array}{l}\text { Pre-test of } \\
\text { pronunciation }\end{array}$} & $\begin{array}{l}\text { Experimental } \\
\text { Group }\end{array}$ & 30 & 7.77 & 2.74 & $\mathbf{0 . 0 6}$ & 58 & $\mathbf{0 . 9 5 5}$ \\
\cline { 2 - 9 } & Control Group & 30 & 7.73 & $\mathbf{1 . 7 0}$ & & & \\
\hline
\end{tabular}

* The mean difference is significant at 0.05 level 
Table (1) shows the mean scores, standard deviations, $t$ - value and its significance of both the control and experimental groups on the pre-test of pronunciation. The mean score of the experimental group is 7.77 whereas the mean score of the control group is 7.73 . The value of $t$ is 0.06 which is non- significant at the 0.05 statistical level. Also, as shown in the table, the p-value is 0.955. This indicated that there were no significant differences between the control and experimental groups on the pre-test and that the two groups were equivalent, which was appropriate for the experiment to be conducted. So, the first hypothesis was verified.

The following figure shows the mean score of the experimental and control group in the application of pre-test of pronunciation.

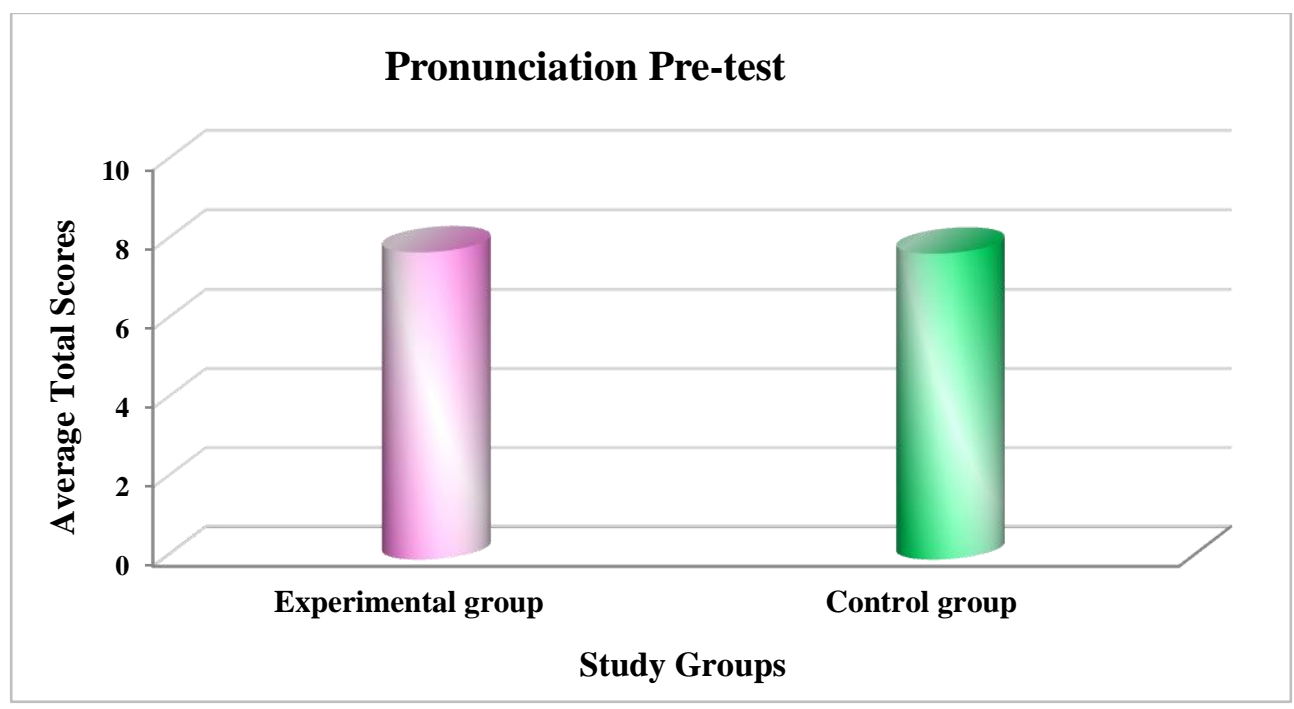

Figure (1) The mean score of the experimental and control group in the pre test

Figure (1) points out that both the experimental group and the control one are equivalent. Table (1) shows that the mean score of 
the experimental group is 7.77 whereas the mean score of the control group is 7.73. Therefore, there were no significant differences

between the control and experimental groups on the pre-test and that the two groups were equivalent.

\section{Verifying the second hypothesis}

The second hypothesis stated there is a statistically significant difference $(\alpha \leq 0.05)$ between the mean score of the control group and experimental group in in the application of the post-test of pronunciation test in favour of the experimental group. To verify the second hypothesis, the researcher used the independent samples ttest to determine if there was any significant difference between the control and experimental group participants in pronunciation in the post application of the test. Table (2) shows results of the statistical analysis.

Table (2) Independent samples t-test for the control and experimental group in the post-test of pronunciation

\begin{tabular}{|l|l|l|l|l|l|l|l||}
\hline \multirow{2}{*}{ Skills } & Study groups & N & MeanSD & \multicolumn{3}{|l|}{ T-test } \\
\cline { 5 - 8 } & & & & & T & DF & $\begin{array}{l}\text { P- } \\
\text { value }\end{array}$ \\
\hline $\begin{array}{l}\text { English } \\
\text { pronunciation test }\end{array}$ & $\begin{array}{l}\text { Experimental } \\
\text { group }\end{array}$ & 30 & 17.70 & 2.44 & 15.63 & 58 & 0.001 \\
\cline { 2 - 8 } & Control group & 30 & 8.13 & 2.30 & & & \\
\hline
\end{tabular}

* The mean difference is significant at 0.05 level

As shown in table (2), the mean scores are 17.70 and 8,13, respectively, while on the pre-test application, as pointed out in table (1), they were 7.77 and 7.73 , respectively. Also, the t-test shows that the $t$-value is (15.63) which is significant at the level (.005). This indicates that there is a significant difference between the control 
and experimental groups in the post application of the pronunciation test. So, the second hypothesis was accepted.

The following figure shows the mean score of the experimental and control group in the application of the post-test of pronunciation.

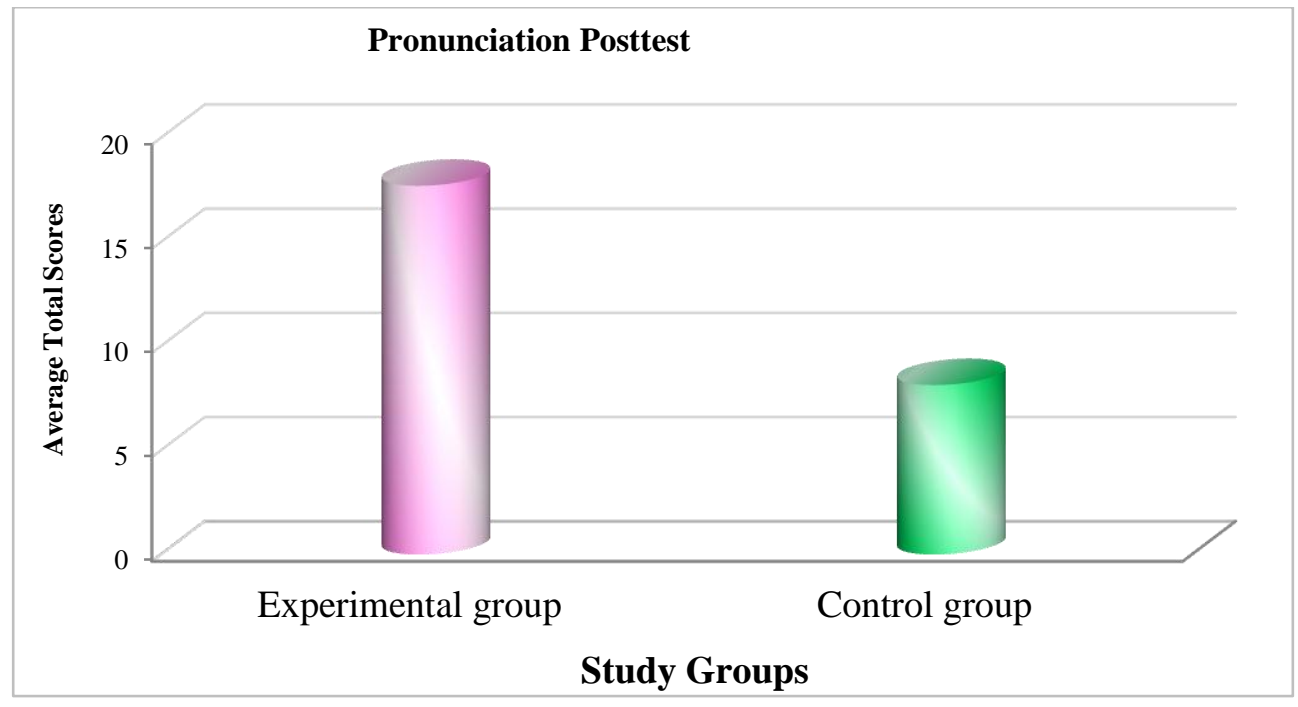

Figure (2) The mean scores of the experimental and control group in the post test

Figure (2) shows that the mean score of the experimental group is higher than the mean score of the control group. It shows the same results as table (2) which reveals that the mean score of the experimental group is 17,70 whereas the mean score of the control group is 8,13 . So, the second hypothesis was accepted.

\section{Verifying the third hypothesis}

The third hypothesis stated that there is a statistically significant difference at $(\alpha \leq 0.05)$ between the pre and post -test scores of the experimental group in pronunciation in favour of the post-test. To verify the third hypothesis, paired samples t-test was used to determine if there was any significant difference between pre 
and post-test scores of the experimental group on the pronunciation test.

Table (3) T-test for the pre-post application of the pronunciation test of the experimental group

\begin{tabular}{|c|c|c|c|c|c|c|c|}
\hline \multirow{2}{*}{ Test } & \multirow{2}{*}{ Test } & \multirow{2}{*}{$\mathbf{N}$} & \multirow{2}{*}{ Mean } & \multirow{2}{*}{ SD } & \multicolumn{3}{|c|}{ T-test } \\
\hline & & & & & $\mathbf{T}$ & DF & P-value \\
\hline \multirow{2}{*}{$\begin{array}{l}\text { English } \\
\text { pronunciation test }\end{array}$} & Pre-test & \multirow{2}{*}{30} & 7.77 & 2.74 & \multirow{2}{*}{21.26} & \multirow{2}{*}{29} & \multirow{2}{*}{0.001} \\
\hline & Post-test & & 17.70 & 2.44 & & & \\
\hline
\end{tabular}

* The mean difference is significant at 0.05 level

Table (3) shows that the mean scores of the experimental group increased from 7.77 to 17.70 . It also shows that the calculated $\mathrm{t}$-value is (21.26) which is significant at 0.05 . This indicates that there is a statistically significant difference between the mean score of the experimental group on the pre and post administration of the pronunciation test in favour of the post administration. So, the third hypothesis was verified.

The following figure shows the mean score of the experimental group in the application of the pre-post-test of pronunciation. 


\section{الجمعية المصرية للقر اعة والمعرفة عضو الجمعية الدولية للمعرفة}

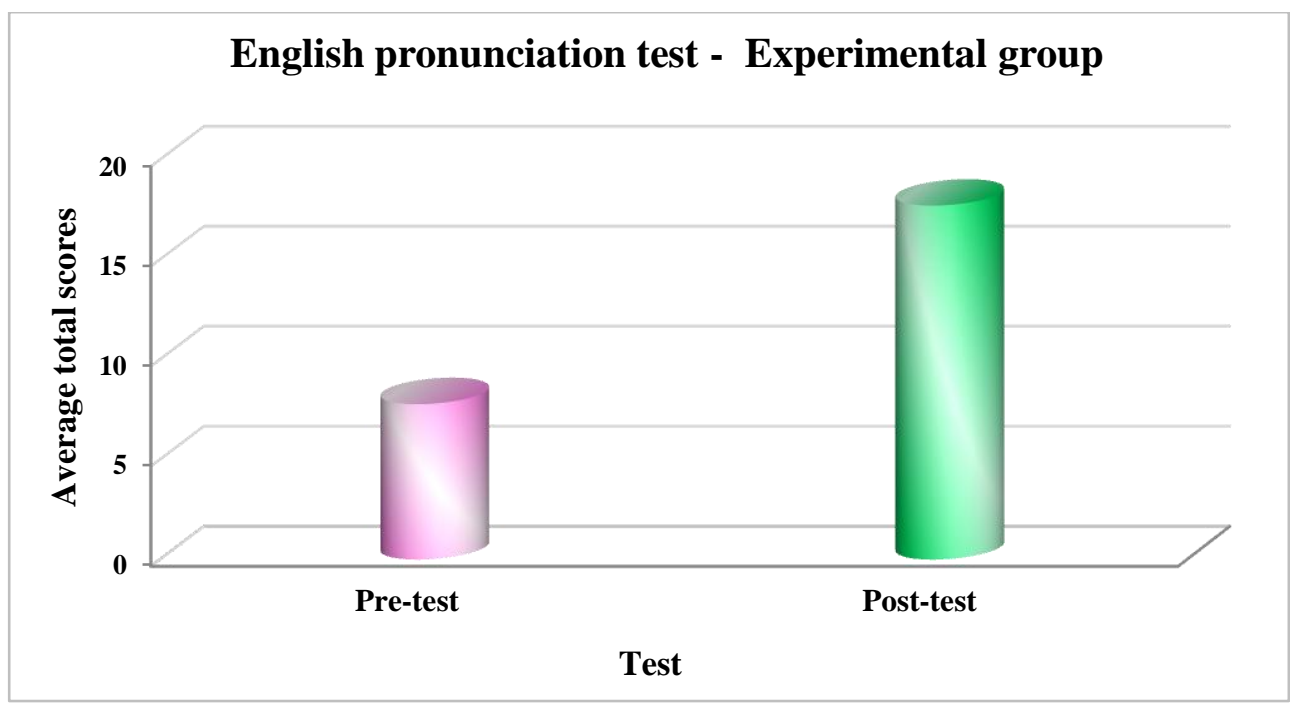

Figure (3) The mean score of the experimental group in the prepost-test of pronunciation

Figure (3) shows that the mean score of the experimental group on the post administration of the pronunciation test is higher than the pre administration of the pronunciation test. It shows the same results as table (3) which reveals that the mean score of the experimental group in the post administration of the pronunciation test increased from 7, 77 to 17, 70 in the post administration of the pronunciation test. So, the third hypothesis was verified. This indicates a considerable improvement in the experimental group students' pronunciation. Consequently, this shows the effectiveness of the linguistic mimicry approach on developing the pronunciation of the first year preparatory school students. This improvement in the students' pronunciation could be due to the fact that students were highly motivated because of the various activities that were used to meet their visual, auditory and kinesthetic learning styles. Another reason could be the use of music, breathing techniques and motivational videos that might have created a free stress atmosphere inside the class room. It could be also attributed to the idea that students had a chance to act and imitate native speakers. 
Table (4) The effectiveness ratio of using linguistic mimicry via neuro-linguistic programming to develop pronunciation

\begin{tabular}{|l|l|l|l|l|l||}
\hline \multirow{2}{*}{ Skills } & Test & Mean & $\begin{array}{l}\text { High Effectivene } \\
\text { score ss ratio }\end{array}$ & $\begin{array}{l}\text { Improveme } \\
\text { nt ratio }\end{array}$ \\
\hline \multirow{2}{*}{ Segmental } & Pre-test & 5.67 & 10 & 0.67 & $29.00 \%$ \\
\cline { 2 - 6 } & Post-test & 8.57 & & & \\
\hline \multirow{2}{*}{$\begin{array}{l}\text { Suprasegment } \\
\text { al }\end{array}$} & Pre-test & 2.10 & 10 & 0.89 & $70.33 \%$ \\
\cline { 2 - 6 } English \\
pronunciation & Post-test & 9.13 & & & \\
\cline { 2 - 6 } & Pre-test & $\mathbf{7 . 7 7}$ & $\mathbf{2 0}$ & $\mathbf{0 . 8 1}$ & $\mathbf{4 9 . 6 7 \%}$ \\
\hline
\end{tabular}

The results illustrated in table (4) indicate the effectiveness ratio of utilizing linguistic mimicry via neuro linguistic programming in developing the first preparatory stage students' pronunciation. The effectiveness ratio of the segmental aspects is 0.67 whereas the effectiveness ratio of the suprasegmental aspects is 0.89 . This indicates that the suprasegmental aspects improved more than the segmental aspects. The effectiveness ratio of the whole test is 0.81. Each of these ratios is greater than 0.6 that Mack Gogyan estimated to judge the effectiveness. So, these results indicate the effectiveness of utilizing linguistic mimicry via neuro linguistic programming in developing first preparatory stage students' pronunciation.

The following figure shows the effectiveness ratio of using linguistic mimicry via neuro-linguistic programming to develop pronunciation 


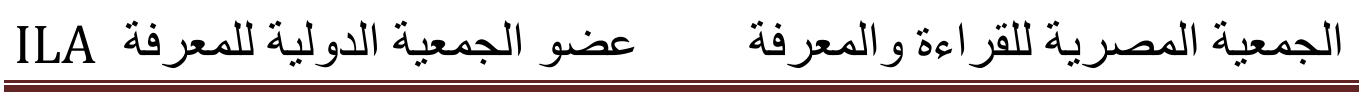

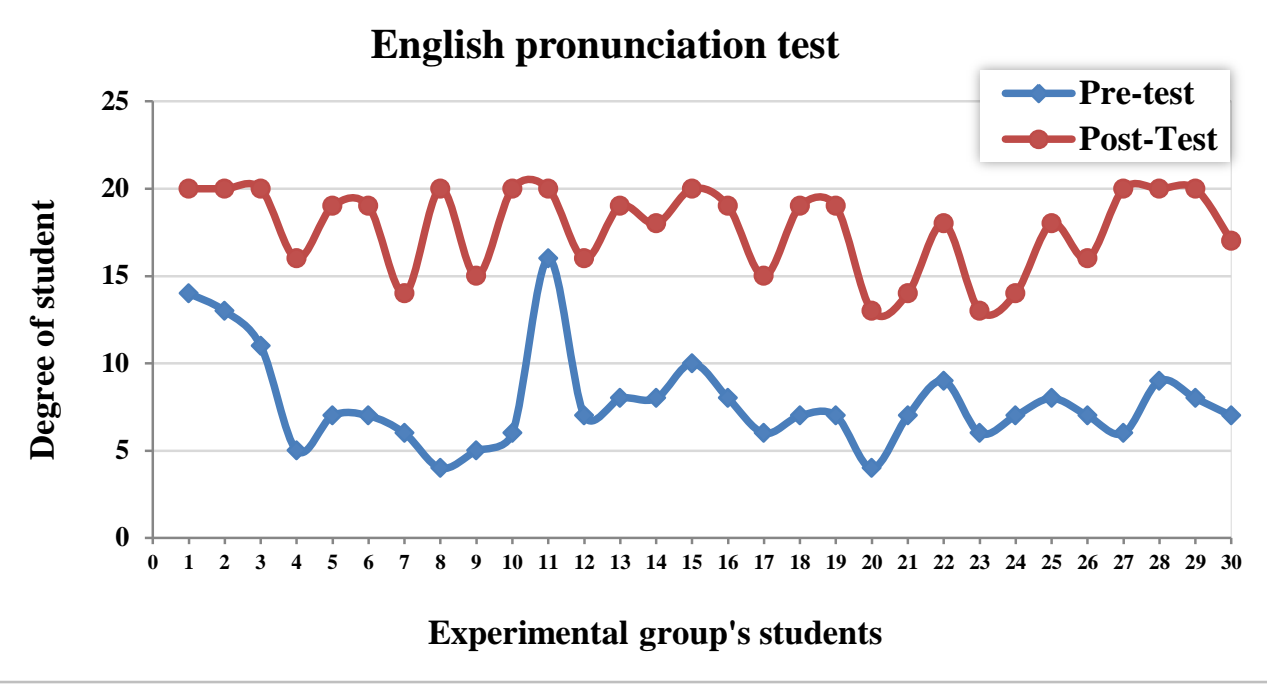

Figure (4) The effectiveness ratio of using linguistic mimicry via neuro-linguistic programming to develop pronunciation

Figure (4) shows that the the suprasegmental aspects improved more than the segmental aspects. This could be because students studied a lot of sounds whereas the studied only two suprasegmental aspects, sentence stress and intonation.

\subsection{Discussion of results}

Results indicate that there is a statistically significant difference between the mean score of the pre and post application of the experimental group in favor of the post application of the pronunciation test. This improvement proves that using the suggested treatment, which was based on utilizing linguistic mimicry via neuro linguistic programming, help develop the students' pronunciation. The results show the effectiveness of using linguistic mimicry, anchoring, reframing, modeling as well as activities based on learning styles (VAK).

There is a consistency between the results of the present study and a number of previous studies. For example, Yates (2003) 
conducted a study in order to test the hypothesis that a whole language approach to ESL pronunciation focusing on suprasegmentals is more effective than concentrating on segmentals in improving native speakers perceptions of accent and comprehensibility of ESL students' pronunciation of English. Participants of the study were two intermediate ESL classes at a community college in Dallas, Texas. One class was taught in the language lab so as to practice repetition of segmentals whereas the other class relied on imitating actors from a television show as well as memorizing scripts. These students mimicked the actors focusing on gestures, suprasegmentals, and paralinguistic cues. The two groups were audio taped speaking about a series of illustrations at the beginning and end of a twelve-week period. This study showed that a whole language approach to ESL pronunciation focusing on suprasegementals through the use of linguistic mimicry is more effective than focusing on segmentals in improving native speaker's perceptions of accent and comprehensibility of ESL students' pronunciation of English. The present study, which utilized linguistic mimicry via NLP techniques, shares the same result that linguistic mimicry is effective in improving pronunciation. Also, the students were audio-taped before and after the treatment.

Furthermore, Caballero \& Rosado (2018) conducted a study in order to investigate how NLP can assist EFL teachers address a troublesome pronunciation issue for Spanish EFL learners: the past ed ending of regular verbs. Participants of the study were 43 students at a university language institute. Two groups were taught using standard techniques of pronunciation and the other two were taught using NLP techniques preceded by oral tasks in which they were motivated to pronounce regular verbs in the past. Data collected included a teacher's log about students' response and attitude to the strategy, a survey to elicit students' motivation and students selfrecorded pronunciation tasks. The results showed that using NLP techniques during teaching affects positively on students' 
pronunciation of the past ending of regular verbs. The present study agrees that using NLP techniques especially anchoring, reframing modeling and activities based on leaning styles help in teaching pronunciation. The present researcher also used teacher's log to identify the students' response towards the treatment.

Abduloh (2018) conducted a study to determine the effectiveness of modeling technique, as one of Neuro Linguistic Programming (NLP) techniques, in reducing students' pronunciation errors. In this study, the researcher used a qualitative approach with descriptive methods. Participants of the study were English education students who shared in the English Spelling Corner (ESC) program. Data was obtained from interviews, observation, and documentation. The results showed that when the students learn English pronunciation by using NLP modeling techniques, they are capable of practicing according to the right way. Modeling technique helps students to pronounce English easier by modeling native speakers in the video material where students can reduce errors in different aspects of pronunciation such as consonants, vowels, intonation, and stress in English syllables. The present study agrees with Abduloh's study (2018) that modeling, which is one of NLP techniques, is effective in teaching pronunciation both segmental aspects of pronunciation such as vowels and consonants and supasegmental ones such as stress and intonation.

Pecha (2012) conducted a study which aimed at reviewing the techniques of neuro-linguistic programming and to ascertain their scientific validity. The study was conducted in two stages. The first stage was to evaluate the theoretical background of NLP and to find out which concepts and techniques are scientifically valid. The second stage was the actual design and testing of the methods in English classes, which involved designing three experiments. The three experiments were performed on three different groups of students. The results revealed that NLP can be incorporated into 
classes of English language and that the techniques make a noticeable change in the learning experience. Moreover, it was proven that reframing technique can be used with all students and positively affects teaching. The present study agrees with peach's study (2012) that NLP reframing technique is effective in teaching English pronunciation.

Further, the results of a study conducted by Saman (2006) agreed with the results of the present study that NLP techniques are effective in English language teaching. Saman's study (2006) aimed to investigate the effects of NLP techniques in learning and teaching English. Participants of the study were 36 students at the Preparatory School at Çağ University, a private university in Mersin. They participated in the questionnaire and the NLP activities. The researcher used some of NLP activities and techniques in the classroom. Results showed that, after implementing NLP activities in the classroom, the learners became more motivated and relaxed and this made the learning process continue in a more effective way. Moreover, these activities enabled the students to develop their basic English skills in English, such as listening, reading, writing, and especially speaking.

In addition, the results of a study conducted by Abinaya and Kumar (2017) indicated the same results of the present study which asserted the effectiveness of NLP techniques in teaching pronunciation. The study aimed at exploring the concepts and techniques of NeuroLinguistic Programming (NLP) and its potential for teaching and learning. Results revealed that NLP techniques can be used in teaching of all language aspects. It can be applied in the regular language classrooms for achieving better participation and results. The techniques are considered thought-provoking and optimistic. NLP techniques could motivate the learners greatly. It enabled the students to think, act and speak positively to meet the heights of achievement. 


\section{Recommendations}

Based on the results of the study, the researcher recommends the following:

\section{Recommendations to Curriculum Designers and Decision Makers}

- Curriculum designers and decision makers should enrich the Egyptian curricula with different pronunciation teaching strategies that make it connected with productive skills.

\section{Recommendations to Teachers of English}

- They should give more attention to teaching pronunciation from the very beginning in order to avoid fossilization.

- Teachers should take into their consideration students' different learning styles during teaching English pronunciation.

- They should use different types of activities that encourage students to speak.

- They should have a good rapport with students as it helps teacher in achieving teaching goals.

\section{Suggestions for further research}

The following recommendations are based on the results of the study:

- The duration of this study was only 8 weeks, so it would be beneficial if similar studies were carried out for longer periods in order to obtain more conclusive results.

- The study revealed that students' performance in the shortterm was impressive; however, there should have been a 
follow-up test to measure its long-term effect. Other studies should address the issue of retention.

- Administering the intervention at different stages (primary and secondary) then comparing at which stage the intervention was more effective.

- Conducting more studies to investigate the effect of using NLP on developing other language skills such as writing, listening and reading.

\section{Conclusion}

The main purpose of the study was to investigate the effectiveness of utilizing linguistic mimicry via neuro-linguistic programming to develop the first year preparatory students' pronunciation. Based on the results reported in chapter four, the following conclusions were drawn:

- Utilizing linguistic mimicry via neuro-linguistic programming was effective in developing the first year preparatory students' pronunciation compared to traditional teaching of pronunciation.

\section{References}

Ahmad, Y. B., \& Abduloh, A. (2018). NLP MODELLING

TECHNIQUE IN REDUCING PRONUNCIATION

ERRORS. English Language Teaching and

Research, 2(1).Retrieved on 26-2-2020 from

http://ejournal.unp.ac.id/index.php/eltar/article/download/102

$\underline{674 / 101060}$ 
Bozoğlan,B.(2010). Is NLP Applicable to ELT? University of Ploiesti Bulletin, Educational Sci, 62(1), 185. Retrieved on 4-2-2020 from:

Burns, A., \& Claire, S. (2003). Clearly speaking: pronunciation in action for teachers. National Centre for English Language Teaching and Research Macquarie University, Sydney.P.6

Caballero, D. R., \& Rosado, N. (2018). Neurolinguistic Programming and Regular Verbs Past Tense Pronunciation Teaching. English Language Teaching, 11(11), 1-18. retrieved on23-4-2020 from https://eric.ed.gov/?id=EJ1193619 Celce-Murcia, M, Brinton,D \& Goodwin, J (1996). Teaching pronunciation: A reference for teachers of English to speakers of other languages. Cambridge: University Press.

Dadour,E.(1990). Evaluating the effectiveness of direct versus indirect teaching of pronunciation in the seventh grade of basic education. Unpublished Master's Thesis, Damietta Faculty of Education, Mansoura University.

El-Fikey,I.(2009). Neuro linguistic Programming and the art of unlimited communication( $2^{\text {nd }}$ edition)( In Arabic) Manar for publishing, Egypt. 
Fleming, N., and Baume, D. (2006) Learning Styles Again:

VARKing up the right tree!, Educational Developments, SEDA Ltd, Issue 7.4, Nov.2006,p4-7.

Gilakjani, A. P. (2012). A study of factors affecting EFL learners' English pronunciation learning and the strategies for instruction. Islamic Azad University, Iran. International Journal of Humanities and Social Science, 2(3)119-128. Gilakjani, A. \& Sabouri, N. (2016). Why Is English Pronunciation Ignored by EFL Teachers in Their Classes? Islamic Azad University, Iran. International Journal of English Linguistics 6(6), P 195

Hişmanoğlu, M. (2006). Current perspectives on pronunciation learning and teaching. Journal of language and linguistic studies, 2(1).Retrieved on 8-2-2020 from file:///C:/Users/e/AppData/Local/Temp/Curent_Perspectives on_Pronunciation_Learning_and_.pdf

Kamal El- Din, A.(2014). The Effectiveness of a strategy designed in the light of Content Based Instruction and Drama Activities in developing the English oral 
Expression skills of preparatory Stage students.

Unpublished Master's Thesis, Faculty of Education, Ain

Shams University.

Mater, S. (2013). Using some communicative activities for developing the EFL speaking skills among Al-Azhar prep stage pupils. Unpublished Master's Thesis, Faculty of Education, Mansoura University.

Murphy, R. J., Gray, S. A., Straja, S. R., \& Bogert, M. C. (2004).

Student learning preferences and teaching implications.

:Educational methodologies. Journal of Dental Education, 68 (8), 859-866.

Revell, J., \& Norman, S. (1997). In your hands: NLP in ELT. Saffire Press, London, P.14

Thornbury, S. (2006). An A-Z of ELT: A Dictionary of Terms and Concepts Used in English Language Teaching. Oxford, UK.: Macmillan Education.

Winch,S.(2005).From Frustration to satisfaction: Using NLP to improve self-expression. In 18th Annual EA Education Conference,English Austrlia,Mercure Hotel,Brisbane,QLD. 
Retrieved on 29-4-2020 from:

file:///C:/Users/e/AppData/Local/Temp/48755-1.pdf

Yates, K. W. (2003). Teaching linguistic mimicry to improve second language pronunciation. MA Degree, University of North

Texas. Retrieved on 11-3-2020 from

https://digital.library.unt.edu/ark:/67531/metadc4164/

Yates, L., \& Zielinski, B. (2009). Give it a go: Teaching

pronunciation to adults. Adult Migrant English Program

(AMEP) Research Centre, Macquarie University.P.11

retrieved on 25-3-2020 from

http://www.ameprc.mq.edu.au/_data/assets/pdf_file/0006/27

$\underline{6135 / \text { interactive_sm.pdf }}$

Zayed, J.(2003). The effectiveness of the dramatic activities the development of the oral performance skills the prep students in English. Unpublished Master's Thesis, Faculty of Education, Mansoura University. 